\title{
El Derecho internacional de las migraciones: entre la crisis y la renovación
}

\author{
International migration Law: \\ between crisis and renewal
}

\author{
José Juste Ruiz \\ Catedrático de Derecho Internacional \\ Universidad de Valencia \\ jose.juste@uv.es
}

\begin{abstract}
Resumen: El régimen internacional de las migraciones actualmente vigente resulta manifiestamente insuficiente para la regulación y gobernanza de los flujos migratorios. La colisión irreductible entre el derecho de las personas a salir de su país y el derecho de los Estados a rechazar la admisión de los migrantes en su territorio ha llevado, en la práctica, a un círculo vicioso cuyos resultados son el aumento de la emigración irregular y la multiplicación de situaciones dramáticas que hieren los sentimientos humanitarios. A la vista de esta situación, las Naciones Unidas han auspiciado la adopción en enero de 2019 de sendos instrumentos que tratan de establecer un nuevo marco para la cooperación internacional en la materia: el Pacto Mundial sobre los Refugiados y el Pacto Mundial para la Migración Segura, Ordenada y Regular. Pero los instrumentos adoptados no han logrado un consenso general que permita prever una pronta solución de los problemas pendientes.
\end{abstract}

Palabras clave: migraciones, refugiados, non-refoulement, derechos humanos

\begin{abstract}
The international migration regime currently in force is manifestly insufficient for the regulation and governance of migration flows. The irreducible collision between the right of persons to leave their country and the right of States to reject the admission of migrants in its territory has led, in practice, to a vicious circle resulting in an increase in irregular migration and the multiplication of dramatic situations that hurt humanitarian feelings. In view of this situation, the United Nations promoted the adoption in January of 2019 of two instruments seeking to establish a new framework for international cooperation in this field: a Global Compact on Refugees and a Clobal Compact on Safe, Orderly and Regular Migration. However, as general consensus on the new instruments has not been reach it seems difficult to foresee a prompt solution of outstanding issues.
\end{abstract}

Keywords: migrations, refugees, non-refoulement, human rights

Sumario: I. INTRODUCCIÓN. II. LA INSUFICIENCIA DEL RÉGIMEN INTERNACIONAL DE LAS MIGRACIONES. a) EI derecho de los migrantes a salir de su país y regresar a él. b) El derecho de admisión del Estado de destino y sus limitaciones. c) Errores de planteamiento y problemas resultantes. III. HACIA UN NUEVO MARCO INTERNACIONAL PARA LAS MIGRACIONES: LAACCIÓN DE LAS NACIONES UNIDAS. a) El Pacto Mundial sobre los Refugiados. b) El Pacto Mundial para la migración segura, ordenada y regular. c) La falta de consenso sobre el nuevo marco global para las migraciones. IV. CONCLUSIÓN.

* Trabajo realizado en el marco de los proyectos de investigación «El pilar ambiental del desarrollo sostenible: evolución en el marco del Derecho internacional y Europeo» (DER2017-85443P, MINECO/AEIFEDER, UE) y «La dimensión ambiental del desarrollo sostenible: evolución jurídica internacional, europea y española» de la Generalitat Valenciana (AICO/2018/137). 


\section{INTRODUCCIÓN}

L as migraciones constituyen un fenómeno natural que se ha producido en todos los tiempos a lo largo de la historia. La aparición del Estado-nación en el siglo XVII, separado de los otros Estados por medio de las fronteras, propició las oleadas migratorias internacionales que se han sucedió al hilo de las grandes transformaciones del mundo contemporáneo: colonización de otros continentes, guerras mundiales, regímenes políticos totalitarios, proceso de descolonización, brecha entre los países desarrollados y los países en desarrollo...

Actualmente, las migraciones constituyen un tema prioritario en la agenda internacional ya que afectan a más de 250 millones de personas (el 3\% de la población mundial), entre los que hay 24,5 millones de refugiados. Las razones que impulsan las migraciones del siglo XXI son múltiples pero tienen su denominador común en la aspiración inveterada de los seres humanos a buscar mejores condiciones de vida allá donde estas puedan alcanzarse, en su tránsito permanente hacia la conquista de la felicidad. En función de las diversas motivaciones que les impulsan a abandonar su país se habla de migrantes forzados (que huyen de la persecución y de los conflictos armados), migrantes económicos (que huyen de la pobreza y la carencia de expectativas de progreso) y migrantes ecológicos (que huyen de los desastres naturales, de la degradación ambiental y de los efectos adversos de la desertización y del cambio climático $)^{1}$. También se hace una distinción entre los migrantes regulares, que han sido admitidos legalmente en el Estado de recepción, y los migrantes irregulares o «ilegales», que han entrado y permanecen en el territorio contraviniendo las leyes del Estado. Todos ellos son, en definitiva, personas que buscan en otras latitudes aquello que no pueden encontrar en su propio país.

Sin embargo, en el mundo globalizado en que vivimos, el derecho de las personas a moverse a través de las fronteras para asentarse en el territorio de otro Estado no está en modo alguno garantizado. Curiosamente, en el marco del proceso de mundialización, la eliminación de las barreras a la libre circulación de mercancías, servicios y capitales, así como el libre flujo de la información y la comunicación, no se han visto acompañados por una eliminación

1 Algunos autores distinguen entre las migraciones «forzadas» (que afectan a las víctimas de situaciones de peligro o coacción) y las migraciones «forzosas» (en las que el desplazamiento de las personas se ve obligado por la fuerza de circunstancias insuperables de orden predominantemente social y económico). GARCía PICAZO, P. «Migraciones: entre la intolerancia y la utopía. Sobre la globalización de la cultura de la pobreza», REEI, n. ${ }^{\circ} 11 / 2016$. 
paralela de las barreras que impiden la libre circulación de las personas a través de las fronteras. El derecho humano a ir y a venir, más natural que la existencia de las fronteras entre los países, no tiene un reconocimiento efectivo en la práctica. Esto constituye sin duda una carencia importante en un mundo que se quiere globalizado y cosmopolita.

De lo anterior se deduce que el fenómeno migratorio es un hecho estructural y sistémico en la sociedad internacional contemporánea ${ }^{2}$ sobre el que, sin embargo, todavía carecemos de una base de conocimientos empíricos suficientemente sólida y cuyo régimen de regulación y gobernanza presenta importantes deficiencias.

\section{LA INSUFICIENCIA DEL RÉGIMEN INTERNACIONAL DE LAS MIGRACIONES}

El esquema jurídico relativo a las migraciones que se ha elaborado hasta hoy en el ámbito del Derecho internacional resulta manifiestamente insuficiente para la regulación y gobernanza de los flujos migratorios. El régimen establecido se sitúa en el punto de encuentro entre dos postulados jurídicos antagónicos: el derecho de las personas a moverse libremente a través de las fronteras ${ }^{3}$ y el derecho de los Estados a rechazar la entrada de los migrantes a su territorio. La tensión irreductible entre este binomio contradictorio se manifiesta en todas las fases del proceso migratorio.

\section{a) El derecho de los migrantes a salir de su país y de regresar a él}

El derecho a salir de cualquier país, incluido el propio, y de regresar a él ha sido siempre reconocido como un derecho de todas las personas. La Declaración universal de los derechos humanos de 1948 afirmó ya en su artículo

2 Así lo ha explicado Javier de Lucas: «los flujos migratorios han alcanzado un carácter sistémico, estructural, del orden mundial que impone el modelo de globalización dominante, son el mascarón de proa de la globalización, movimientos transfronterizos de dimensiones planetarias, que desbordan la capacidad de reacción del Estado nación». DE LUCAS MARTIN, J. «Sobre las políticas de inmigración en un mundo globalizado», en Anuario de la Facultad de Derecho de la $U A M, 7,2003$, pp. 24.

3 La libertad de circulación de las personas constituye un atributo fundamental de la condición humana. Sobre la base del ius comunicationis de Vitoria, este principio ha tenido una amplia acogida en el Derecho internacional clásico, pero en la actualidad su reconocimiento se enfrenta a muchas reticencias por parte de los Estados. Ver PEÑA, L. «El derecho del individuo a circular libremente y a escoger su residencia», La balsa de la medusa, n² 21, Madrid, 1992, pp. 7-8. 
13,2 que «toda persona tiene el derecho de salir de cualquier país, incluso el propio». Con mayor detalle, el Pacto internacional de derechos civiles y políticos de 1966 afirma en su artículo 12 que:

1. Toda persona que se halle legalmente en el territorio de un Estado tendrá derecho a circular libremente por él y a escoger libremente en él su residencia.

2. Toda persona tendrá derecho a salir libremente de cualquier país, incluso del propio.

3. Los derechos antes mencionados no podrán ser objeto de restricciones salvo cuando éstas se hallen previstas en la ley, sean necesarias para proteger la seguridad nacional, el orden público, la salud o la moral públicas o los derechos y libertades de terceros, y sean compatibles con los demás derechos reconocidos en el presente Pacto.

4. Nadie podrá ser arbitrariamente privado del derecho a entrar en su propio país.

Como se aprecia con claridad, este artículo proclama tanto el derecho de libre circulación interna (es decir el derecho a circular en el interior del Estado de residencia legal) como el derecho de libre circulación externa (es decir el derecho a salir libremente de cualquier país incluido el propio para dirigirse a otro país). Así lo ha reconocido el Comité de derechos humanos del Pacto internacional de derechos civiles y políticos de 1966 en su observación gene$\mathrm{ral} \mathrm{n}^{\circ} 27$ en la que afirma que «la libertad de circulación (tanto en el interior como en el exterior) es una condición indispensable para el libre desarrollo de la persona», añadiendo que:

La libertad de salir del territorio de un Estado... incluye el viaje temporal al extranjero y la partida en caso de emigración permanente. Igualmente, el derecho de la persona a determinar el Estado de destino es parte de la garantía jurídica ${ }^{4}$.

El derecho de toda persona a salir del territorio del Estado no es un derecho absoluto, sino que puede estar sometido a condiciones razonables tales como la posesión de los títulos de viaje pertinentes (pasaporte). Pero, como ha señalado con claridad el Comité de derechos humanos, «el derecho a salir del

4 Observación general n 27 , par. 1 y par. 8. 
Estado debe incluir el de obtener los documentos de viaje necesarios», por lo que la emisión de un pasaporte a las personas que lo solicitan es una obligación del Estado y un derecho de dichas personas 5 .

\section{b) El derecho de admisión del Estado de destino y sus limitaciones}

El régimen internacional vigente confiere al Estado de destino de los migrantes el derecho soberano a decidir sobre su admisión o no admisión en el territorio. En teoría, podría hablarse de un derecho a emigrar, pero no de un derecho a inmigrar a un determinado Estado ya que, en la práctica, el migrante sólo puede entrar en otro Estado con el consentimiento del soberano territorial. Esta situación conduce a resultados particularmente dramáticos en el caso de los migrantes rescatados en situaciones de peligro en el mar y cuyo desembarco en un lugar seguro se enfrenta a menudo con el rechazo de su admisión por los Estados costeros ${ }^{6}$. Como ha subrayado el profesor

5 El Comité de derechos humanos ha señalado este respecto que «En la práctica de los Estados se encuentra una gama... variada de obstáculos que hacen más difícil la salida del país, sobre todo de sus propios nacionales. Entre esas normas y prácticas figuran la falta de acceso de los solicitantes a las autoridades competentes y la falta de información sobre los requisitos; la obligación de solicitar formularios especiales para conseguir los documentos oficiales de solicitud de pasaporte; la necesidad de certificados o declaraciones de empleadores o de familiares en apoyo de la solicitud; la descripción exacta del itinerario; la expedición de pasaportes sólo previo pago de tasas elevadas que exceden considerablemente el costo de los servicios prestados por la administración; las demoras injustificadas en la expedición de los documentos de viaje; las restricciones a que viajen juntos miembros de la familia; el requisito de depositar una fianza de repatriación o estar en posesión de un billete de vuelta; el requisito de haber recibido una invitación del Estado de destino o de personas que vivan en él; el hostigamiento de los solicitantes, por ejemplo, mediante intimidación física, detención, pérdida del empleo o expulsión de sus hijos de la escuela o la universidad; la negativa a expedir un pasaporte so pretexto de que el solicitante perjudica el buen nombre del país.» Observación general n 27, par. 17.

6 Los capitanes de los buques tienen la obligación de prestar auxilio a las personas que se encuentran en peligro en el mar, de acuerdo con lo previsto en la Convención de las Naciones Unidas sobre el Derecho del Mar de, 1982 (art. 98) y en otros convenios de la Organización Marítima Internacional (OMI) tales como la Convención internacional de 1974 para la salvaguardia de la vida humana en el mar (Convención SOLAS enmendada), regla V/33.1; V/7.1 y la Convención internacional de 1979 sobre la búsqueda y salvamento marítimos (Convención SAR enmendada) capítulo 2, párrafo 2.1.10 y capítulo 1, párrafo 1.3.2. La OMI, mediante la Resolución MSC. 167(78) de 20 de mayo de 2004, ha establecido un procedimiento indicativo que postula la pronta liberación de las responsabilidades del capitán y del buque que realizan el rescate, el trato humanitario a los supervivientes y su conducción a un lugar seguro en un plazo razonable bajo 
Scovazzi, se trata de un derecho asimétrico al que el autor aplica la lógica demoledora del absurdo:

«si cada Estado dispone del derecho soberano de admitir o rechazar extranjeros en su territorio, si un emigrante no es admitido en ningún Estado ¿Dónde podrá establecerse? ¿En el alta mar? ¿En alguna parte de la Antártida que no es reivindicada por ningún Estado? o ¿En la Luna o en otro cuerpo celeste?» ${ }^{7}$.

La antinomia normativa resultante puede encontrar alguna vía de mitigación por la existencia de ciertas normas internacionales, derivadas de consideraciones humanitarias que limitan la competencia discrecional del Estado en materia de entrada de extranjeros, como sucede en el caso de las personas que sufren persecución en sus países de procedencia. La Declaración Universal de Derechos Humanos de 1948 afirmó ya en su artículo 13,1 que «en caso de persecución, toda persona tiene derecho a buscar asilo, y a disfrutar de él, en cualquier país» y la Declaración sobre el asilo territorial de 1967 añade en su artículo 3, 1 que ninguna de las personas que solicita asilo «será objeto de medidas tales como la negativa de admisión en la frontera... o la expulsión o devolución obligatoria a cualquier Estado donde pueda ser objeto de persecución ${ }^{8}$. La Convención de Ginebra sobre el Estatuto de los Refugiados de 1951, cuyo ámbito de aplicación territorial y personal fue extendido por el Protocolo de 1967, obliga a los Estados partes a examinar con benevolencia las peticiones de quienes solicitan refugio, prohibiendo en todo caso su expulsión y devolución al país en el que sufren persecución (principio de non refoulement), conforme a lo dispuesto en su artículo 33:

Ningún Estado contratante podrá, por expulsión o devolución, poner en modo alguno a un refugiado en las fronteras del territorio donde su vida o

la responsabilidad «del Gobierno de la región SAR donde fueron rescatados los supervivientes» (Resolución MSC.167(78), Directrices respecto de la actuación con las personas rescatadas en el mar, par 2, 5). Sin embargo, dado el carácter meramente declarativo de este procedimiento (soft law) y la falta de concreción de sus disposiciones, los problemas que afectan al desembarco de los migrantes rescatados en el mar en un lugar seguro distan mucho de haber quedado resueltos.

7 Scovazzi, T. «Il respingimento di un drama ummano collettivo e le sue conseguenze», en Antonucci, A.; Papanicolopulu, I.; Scovazzi, T. (coords.), L'immigrazione irregolare via mare nella giurisprudenza italiana e nell'esperienza europea, Turín (Giappichelli), 2016, p. 66

8 Resolución 2312 (XXII) Declaración sobre el Asilo Territorial, adoptada por la Asamblea General el 14 de diciembre de 1967. 
su libertad peligre por causa de su raza, religión, nacionalidad, pertenencia determinado grupo social u opiniones políticas?

Sin embargo, la Convención sobre los refugiados de 1949 se aplica únicamente a las personas que tienen fundados temores de ser perseguidas «por motivos de raza, religión, nacionalidad, pertenencia determinado grupo social u opiniones políticas». Además, la Convención no garantiza a la persona perseguida la obtención de la condición de refugiado, sino que únicamente obliga al Estado de recepción a adoptar medidas para «no poner en modo alguno a un refugiado en las fronteras de territorios donde su vida su libertad peligren ${ }^{10}$. Las personas que sufren persecución por otros motivos o que huyen de los conflictos armados, aunque no reúnan las condiciones para ser considerados refugiados de acuerdo con la Convención de Ginebra de 1951, tienen también derecho a no ser devueltos al país donde sufren persecución (non refoulement) ${ }^{11}$. En cambio, los migrantes económicos y ecológicos no están protegidos por el principio de non refoulement y pueden, por lo tanto, ser declarados no admisibles en el territorio del Estado de destino y devueltos al país de procedencia.

En el proceso de decisión sobre la admisión o rechazo de los migrantes, cualquiera que sea su naturaleza o condición, el Estado territorial debe respe-

9 El principio de non refoulement ha sido proclamado también por la Convención contra la tortura y otros tratos o penas crueles inhumanos o degradantes de 1948 (art. 3) así como por diversos instrumentos convencionales de ámbito regional: Convención americana sobre derechos humanos de 1969 (art. 22) y Convención de la Unión Africana sobre cuestiones relativas a los problemas de los refugiados en África de 1969. Asimismo, la Comisión de Derecho Internacional de las Naciones Unidas (CDI) ha incluido diversas disposiciones sobre la prohibición de expulsión y devolución de personas en el proyecto de artículos sobre la «expulsión de extranjeros», aprobado en los meses de junio y agosto de un 2014.

10 Por otra parte, el propio artículo 33, 2 admite una excepción a la regla del non refoulement en los casos en los que «el refugiado sea considerado, por razones fundadas como un peligro para la seguridad del país donde se encuentra, o que habiendo sido objeto de una condena definitiva por un delito particularmente grave, constituya una amenaza para la comunidad de tal país.» Además, ni la Convención ni el Protocolo incluyen disposición alguna sobre el procedimiento aplicable a la determinación de la condición de refugiado, por lo que el Estado territorial podrá regularlo discrecionalmente. Como resultado de ello, los refugiados corren el riesgo de ser enviados de un país a otro hasta encontrar un Estado que los admita (son los llamados «refugiados en órbita»).

11 Cabe afirmar así que el principio de non refoulement de las personas que sufren persecución ha pasado a formar parte del Derecho internacional general o consuetudinario. Ver: OIM, International Migration Law Unit. Information Note on the Principle of Non-Refoulement, April 2014, p. 4. Ver también: Comité de Derechos humanos, Observación General no 15 , par 1 y n ${ }^{\circ} 31$, par. 10 . 
tar ciertas limitaciones que derivan del Derecho internacional de los derechos humanos ${ }^{12}$. Entre estas limitaciones cabe señalar, además del derecho de non refoulement de las personas que sufren persecución: la prohibición de un trato discriminatorio, la prohibición de toda detención o retención arbitrarias, el derecho de acceso a las autoridades consulares, la prohibición de las devoluciones en caliente y de las expulsiones colectivas y el derecho de los niños al reagrupamiento familiar. Sin embargo, hay que señalar que éstas garantías procesales únicamente comienzan a aplicarse cuando los migrantes se encuentran físicamente en el territorio del Estado y no antes, por lo que su aplicación resulta muy problemática en el caso de fronteras fortificadas con vallas, muros u otras barreras físicas.

\section{c) Errores de planteamiento y problemas resultantes}

Los problemas del régimen internacional de las migraciones derivan en realidad de la adopción de ciertos enfoques metodológicos erróneos en el punto de partida.

Se ha pretendido así aportar soluciones nacionales a un problema que es esencialmente internacional, relegando la gestión de las migraciones a la acción regulatoria de cada Estado desde una perspectiva exclusivamente nacional. Este prisma conceptual, que identifica y confunde la migración con la extranjería, resulta particularmente inconveniente e inadaptado a una situación que tiene una dimensión genuinamente internacional y cuyo tratamiento efectivo no puede realizarse por cada Estado actuando de un modo aislado. Además, la huida hacia el unilateralismo y la política del «sálvese quien pueda» ignora que en materia migratoria los roles no están claramente repartidos y que todos los Estados son a la vez países de salida, de tránsito y de recepción de migrantes. Asimismo, la perspectiva regulatoria basada en la consideración de los derechos respectivos de las personas que migran y de

12 Los instrumentos que constituyen el núcleo fundamental del Derecho internacional de los derechos humanos son: el Pacto internacional de derechos civiles y políticos y el Pacto internacional de derechos económicos sociales y culturales de 1966; la Convención internacional sobre la eliminación de todas las formas de discriminación racial de 1965; la Convención contra la tortura y otros tratos o penas crueles, inhumanos o degradantes, de 1984; la Convención sobre la eliminación de todas las formas de discriminación contra la mujer de 1979; la Convención sobre los derechos del niño de 1989; y la Convención internacional sobre la protección de los derechos de todos los trabajadores migratorios y sus familias de 1990. 
los Estados afectados por la migración conduce a colisiones irreductibles que se resuelven inevitablemente mediante soluciones paradójicas que favorecen a la parte más fuerte: el Estado territorial. Como dijo el Juez A.A. Cançado Trinidade, en 2003:

A pesar de encontrarse hoy día reconocido el derecho a emigrar, como corolario del derecho a la libertad de movimiento, los Estados todavía no han reconocido el derecho correlato de inmigrar, creando así una situación que ha generado incongruencias y arbitrariedades...al perpetuar, de ese modo, las incertidumbres e inconsistencias, los Estados responsables por esta situación han dejado de actuar a la altura de sus responsabilidades como sujetos del Derecho Internacional el derecho de gentes. Y han creado más problemas tanto para numerosos individuos directamente afectados como, en última instancia, para sí mismos, al contribuir indirectamente para la formación de inmigrantes $\ll$ ilegales ${ }^{13}$.

Por otra parte, las reglas de Derecho internacional aplicables al proceso migratorio contemplan únicamente algunos aspectos aislados de un fenómeno que es complejo y multidimensional, ignorando o descuidando otros aspectos igualmente importantes. Las migraciones internacionales han podido describirse así como la expresión de una relación triangular entre una persona, el Estado en el que vive y el Estado de destino. Sin embargo, la situación migratoria evoca en realidad una relación poliédrica en la que aparecen también otros actores y elementos relevantes: los países de tránsito, las redes de migrantes en los países de origen y de destino, las posibilidades de empleo en este último, las responsabilidades de los transportistas legales o ilegales (traficantes), la labor de las organizaciones no gubernamentales asistenciales y las razones que impulsan a los inmigrantes a escapar. ${ }^{14}$ Estamos, por tanto, en presencia de un conjunto de relaciones entre diversos individuos, grupos sociales, organismos institucionales y Estados, que presentan una gran variedad y complejidad.

Aunque existen algunos convenios multilaterales, regionales y bilaterales relativos a las migraciones, especialmente en el ámbito humanitario, que se aplican de manera más o menos completa y rigurosa, no existe un corpus aca-

13 Voto Concurrente a la Opinión Consultiva OC-18/03 de 17 de setiembre de 2003, solicitada por los Estados Unidos Mexicanos, Condición Jurídica y Derechos de los Migrantes Indocumentados.

14 Ver Gerber, J-D., «Introduction», en A. Aleinikoff, Le droit international et la migration: Tour d'borizon, Genève (Organisation Internationale pour les Migrations), 2002. p. 13-14. 
bado de principios y reglas aplicables a la cooperación entre los Estados en esta materia. La situación tampoco es mucho mejor en el plano institucional donde, al margen de los organismos que se ocupan de los refugiados como el ACNUR, solo existe la Organización Internacional para las Migraciones (OIM) «cuyas competencias son muy limitadas y su capacidad decisoria y de imposición sobre los Estados inexistente» ${ }^{15}$.

\section{HACIA UN NUEVO MARCO INTERNACIONAL PARA LAS MIGRACIONES: LA ACCIÓN DE LAS NACIONES UNIDAS}

Las importantes deficiencias (e incongruencias) que afectan al régimen internacional de las migraciones han tratado de paliarse mediante diversos procesos de diálogo para mejorar la situación ${ }^{16}$ y han llevado a las Naciones Unidas a promover varias iniciativas para afrontar el desafío global que estas plantean en la actualidad.

Los primeros pasos de las Naciones Unidas hacia una nueva regulación y gobernanza de las migraciones se dieron en el año 2004 con la adopción por la Asamblea General de la resolución 59/241 sobre «Migración internacional y desarrollo» ${ }^{17}$, en la que se ponía de relieve los beneficios que las migraciones podían aportar a los países de origen, de tránsito y de destino. La resolución de la AG reconoce «la importante contribución que hacen los migrantes y la migración al desarrollo» así como «los beneficios que la migración internacional puede reportar a los migrantes, sus familias, las sociedades de acogida y sus comunidades de origen». También observa la adhesión general al multiculturalismo, el reconocimiento de los efectos desiguales de los beneficios de la globalización que han contribuido a generar grandes movimientos de poblaciones y la necesidad de adoptar políticas y tomar medidas para reducir el costo de las transferencias de fondos de los migrantes a los países en desarrollo.

15 PÉrez-Prat Durbán, L., «Inmigración y Derecho internacional: ¿un acuerdo imposible?», en Problemas actuales de la inmigración, Cursos de Derechos Humanos de Donosti-San Sebastián, vol. VII, pp. 138-139.

16 Tales como la «Iniciativa de Berna» lanzada por el gobierno suizo en junio de 2001, el «Diálogo internacional sobre las migraciones» iniciado por la Organización Internacional para las Migraciones en noviembre de 2001 o la llamada «Iniciativa Nansen» para la protección de las personas desplazadas como consecuencia de desastres naturales y del cambio climático de 2015.

17 A/RES/59/241, de 22 de diciembre de 2004. 
La idea de la contribución positiva de las migraciones al desarrollo sostenible fue recogida también en la resolución de 25 de septiembre de 2015 titulada «Transformar nuestro mundo: la Agenda 2030 para el Desarrollo Sostenible», cuyo párrafo 29 afirma:

Reconocemos la positiva contribución de los migrantes al crecimiento inclusivo y al desarrollo sostenible. Reconocemos también que la migración internacional es una realidad pluridimensional de gran pertinencia para el desarrollo de los países de origen, tránsito y destino que exige respuestas coherentes e integrales. Cooperaremos en el plano internacional para garantizar la seguridad, el orden y la regularidad de las migraciones, respetando plenamente los derechos humanos y dispensando un trato humanitario a los migrantes, sea cual sea su estatus migratorio, y a los refugiados y los desplazados. Esa cooperación también deberá fortalecer la resiliencia de las comunidades que acogen a los refugiados, particularmente en los países en desarrollo. Subrayamos que los migrantes tienen derecho a regresar a su país de nacionalidad y recordamos que los Estados deben velar por que se reciba adecuadamente a los nacionales que regresen a su país.

En ese mismo año 2015 la Asamblea General decidió convocar una reunión plenaria de alto nivel para examinar la cuestión de los desplazamientos masivos de refugiados y migrantes ${ }^{18}$. La reunión se celebró el 19 de septiembre de 2016 y, sobre la base de un informe presentado por el Secretario General ${ }^{19}$, adoptó la «Declaración de Nueva York para los refugiados y los migrantes» ${ }^{20}$. La Declaración de Nueva York se centra en los grandes desplazamientos de refugiados y migrantes y enumera una serie de compromisos generales que se aplican a ambas categorías de personas y otros compromisos específicos que se aplican únicamente a los refugiados o únicamente a los migrantes. La Declaración pretende reforzar los derechos de los refugiados y los migrantes, ocupándose de las causas profundas de los desplazamientos y estableciendo un criterio de responsabilidades compartidas en cuya virtud los países y las comunidades de acogida de un gran número de refugiados

18 Ver: Decisión 70/539, Reunión plenaria de alto nivel de la Asamblea General sobre la respuesta para hacer frente a los desplazamientos masivos de refugiados y migrantes. Doc. A/70/49 (vol. II) p. 13.

19 A/70/59, «En condiciones de seguridad y dignidad: respuesta a los grandes desplazamientos de refugiados y migrantes», Informe del Secretario General.

20 A/RES/71/1, Declaración de Nueva York para los refugiados y los migrantes. 
recibieran el sostén de la Comunidad internacional. En tal sentido, el párrafo 68 de la Declaración reconoce:

la importancia que reviste la cooperación internacional para el régimen de protección de los refugiados (y) la carga que imponen los grandes desplazamientos de refugiados en los recursos nacionales, especialmente en el caso de los países en desarrollo. Para atender las necesidades de los refugiados y los Estados de acogida, nos comprometemos a repartir más equitativamente la carga y la responsabilidad de acoger y dar apoyo a los refugiados del mundo, teniendo en cuenta las contribuciones hechas y las diferentes capacidades y recursos de los distintos Estados.

La Declaración incluye un anexo 1, que contiene el «Marco de respuesta integral para los refugiados», y un anexo II titulado «Hacia un pacto mundial para la migración segura, ordenada y regular» que marca el inicio de un proceso de negociación intergubernamental con este objetivo.

\section{a) El Pacto Mundial sobre los Refugiados}

Conforme a los compromisos asumidos en virtud de la Declaración de Nueva York de 2016, el Alto Comisionado de las Naciones Unidas para los Refugiados (ACNUR) preparó el «Pacto mundial sobre los refugiados» que, además de reproducir el marco de respuesta integral para los refugiados, debía contener un programa de acción que detallara las medidas a adoptar por los Estados y las otras partes interesadas para su desarrollo y aplicación efectiva.

El Pacto mundial sobre los refugiados elaborado por ACNUR fue presentado a la Asamblea General en su informe correspondiente al año 2018 para su aprobación. El Pacto mundial sobre los refugiados (en inglés Global Compact on Refugees) afirma en su propio texto que «no es jurídicamente vinculante» pero representa la voluntad política y la ambición de la Comunidad internacional en su conjunto de fortalecer la cooperación y la solidaridad con los refugiados y los países de acogida afectados «mediante contribuciones voluntarias para lograr resultados colectivos y avanzar hacia los objetivos previstos» ${ }^{21}$. El Pacto se basa en el régimen establecido por la Convención sobre los refugiados de 1951 y tiene por objeto principal sentar las bases para una distribución previsible y equitativa de

21 Ver: A/73/12 (Parte II). Informe del alto Comisionado de las Naciones Unidas para los Refugiados, Parte II, Pacto mundial sobre los refugiados, par. 4 
la carga y la responsabilidad entre todos los Estados miembros de las Naciones Unidas y otras partes interesadas pertinentes. Los objetivos del Pacto mundial en su conjunto se resumen en: i) aliviar las presiones sobre los países de acogida; ii) promover la autosuficiencia de los refugiados; iii) ampliar el acceso a las soluciones que impliquen a terceros países; y iv) favorecer en los países de origen condiciones que propicien un retorno en condiciones de seguridad y dignidad.

El contenido sustantivo del Pacto mundial sobre los refugiados se concreta en dos partes complementarias. En primer lugar, se reproduce literalmente el Marco de Respuesta Integral para los Refugiados contenido en la Declaración de Nueva York de 2016, cuyos aspectos fundamentales son: la recepción y admisión de refugiados, el apoyo para la satisfacción de sus necesidades inmediatas y persistentes, el apoyo a los países y las comunidades de acogida y las soluciones duraderas. En segundo lugar, se desarrolla un Programa de Acción más detallado y complejo que contiene sendas secciones relativas a: 1) los mecanismos de distribución de las cargas y responsabilidades con respecto a los flujos de refugiados; 2) los ámbitos específicos que requieren apoyo, tales como la recepción y admisión de los refugiados, la atención a sus necesidades y el apoyo a las comunidades de acogida; y 3) la búsqueda de soluciones duraderas para los problemas de los refugiados. Entre estas soluciones se señala el apoyo a los países de origen y la prioridad de la repatriación voluntaria, el reasentamiento de los refugiados en condiciones idóneas, las vías complementarias para la admisión en terceros países y la integración local y otras soluciones locales.

El Pacto Mundial sobre los Refugiados contenido en el informe del ACNUR fue aprobado por la Asamblea General el 17 de diciembre de 2018 por 181 votos a favor, 2 en contra (Estados Unidos y Hungría) y 3 abstenciones (República Dominicana, Eritrea y Libia) ${ }^{22}$.

\section{b) El Pacto Mundial para la Migración Segura, Ordenada y Regular}

Las negociaciones intergubernamentales para la aprobación de un Pacto mundial para una migración segura, ordenada y regular se iniciaron en 2016 y su última fase se desarrolló en seis períodos de sesiones celebrados en Nueva York entre febrero de 2018 y julio de $2018^{23}$.

22 Ver A/RES/73/151 y GA/12107.

23 Ver: A/RES/71/280, Modalidades para las negociaciones intergubernamentales del pacto mundial para una migración segura, ordenada y regular. 
Las negociaciones culminaron con la adopción del texto del Pacto mundial para la migración (en inglés Global Compact on Migration) que afirma ser un documento «no vinculante jurídicamente», que pretende ofrecer un marco de cooperación internacional entre todas las instancias pertinentes, respetando la soberanía de los Estados y sus obligaciones en virtud del Derecho internacional ${ }^{24}$. El Pacto mundial para las migraciones aparece así, no como un instrumento normativo obligatorio, sino como un procedimiento de diálogo inspirado en una concepción común, en las responsabilidades compartidas y en la unidad de propósito. Sus principios rectores se recogen en el párrafo 15 del texto y son los siguientes: a) voluntad de centrase en las personas (dimensión humana); b) necesidad de la cooperación internacional, c) reafirmación de la soberanía del Estado para determinar su política migratoria, d) respeto del Estado de derecho, las garantías procesales y el acceso a la justicia, e) contribución de las migraciones al desarrollo sostenible, f) protección de los derechos humanos, no regresión y no discriminación, g) perspectiva de género $h$ ) perspectiva infantil, i) enfoque intergubernamental y j) enfoque pansocial ${ }^{25}$. La orientación estratégica del Pacto se basa en mejorar los conocimientos empíricos y la información sobre las migraciones, en potenciar su dimensión humana y en hacer valer los aspectos positivos que estas pueden tener para el desarrollo sostenible en los países de origen, de tránsito y de destino.

Sobre estas bases, el Pacto mundial establece un marco de cooperación que consta de 23 objetivos e incluye también medidas de aplicación, seguimiento y examen. Los 23 objetivos para la migración segura, ordenada y regular pueden reagruparse en torno a los siguientes ejes:

a) recopilar y utilizar datos exactos y desglosados para formular políticas con base empírica (objetivos 1 y 17).

b) mejorar las condiciones en los países de origen, minimizando los factores estructurales que obligan a las personas a abandonar su país (objetivo 2)

c) mejorar las condiciones en las que se realiza la migración, proporcionando información sobre sus distintas etapas, aumentando la disponibilidad de las vías de migración regular y la contratación y garantías de trabajo decente en el país de acogida (objetivos 3, 4, 5, 6, 9).

24 A/RES/73/195, Pacto Mundial para la Migración Segura, Ordenada y Regular, par. 7.

25 Ibid., par. 15. 
d) adoptar una visión humanitaria y reducir la vulnerabilidad en la migración, salvando vidas y reforzando la respuesta transnacional frente al tráfico ilícito de migrantes (objetivos 7, 8, 9, 10)

e) Mejorar la gestión de las fronteras de manera integrada, segura y coordinada, aumentando la certidumbre y previsibilidad de los procedimientos y utilizando la detención de migrantes sólo como último recurso (objetivos 11, 12, 13, 14).

f) mejorar la condición de los migrantes en el Estado de recepción (objetivos 15, 16, 17, 18, 19, 20).

g) Facilitar el regreso, la readmisión y la reintegración sostenible de los migrantes (objetivos 21, 22).

h) Fortalecer la cooperación internacional y las alianzas mundiales para la migración segura, ordenada y regular (objetivo 23).

Para asegurar su aplicación efectiva, el Pacto Mundial para las migraciones contempla el establecimiento de un mecanismo de creación de capacidad, una plataforma mundial de conocimientos como fuente de datos abiertos en línea y un mecanismo de seguimiento y examen que será revisado en el Foro de Examen de la Migración Internacional que se celebrará cada cuatro años a partir de 2022.

El texto negociado y acordado del Pacto Mundial para la migración segura, ordenada y regular fue remitido para su aprobación por una Conferencia intergubernamental que se celebró en Marrakech los días 10 y 11 de diciembre de $2018^{26}$ y fue ulteriormente devuelto a la Asamblea General que lo «hizo suyo» mediante una resolución adoptada el 19 de diciembre de $2018^{27}$.

\section{c) La falta de consenso sobre el nuevo marco mundial para las migraciones}

La historia del difícil proceso de elaboración del nuevo arco mundial sobre las migraciones en el seno de las Naciones Unidas da muestra de las dificultades que todavía encuentra la formación de un consenso global sólido sobre el tema migratorio.

El Pacto Mundial sobre los migrantes fue preparado a través de un proceso de negociación intergubernamental abierto que duró más de dos años. En

\footnotetext{
26 Ver: A/RES/72/244, Modalidades para la Conferencia Intergubernamental Encargada de Aprobar el Pacto Mundial para una Migración Segura, Ordenada y Regular.

27 A/RES/73/195. Pacto Mundial para la Migración Segura, Ordenada y Regular.
} 
otoño de 2017 los Estados Unidos abandonaron el proceso negociador y su actuación fue seguida por otros países en los meses siguientes. La Conferencia de Marrakech, que adoptó el texto del Pacto Mundial sobre las migraciones, contó con la presencia de 162 de los 194 miembros de la Organización, pero entre los 30 Estados que no asistieron a la cita había ausencias clamorosas tales como los Estados Unidos, Australia, Libia, Israel, Suiza, Ucrania y diversos Estados miembros de la Unión Europea (Austria, Bulgaria, Eslovaquia, Estonia, Hungría, Irlanda, Italia, Polonia y República Checa) ${ }^{28}$.

La situación empeoró en la votación de la Asamblea General que hizo suyo el Pacto mundial, donde se produjeron 152 votos a favor, 5 en contra (Estados Unidos, Hungría, Israel, Polonia y República Checa) y 12 abstenciones (entre ellas Australia, Italia, Chile, Rumania y Suiza). En su explicación de voto ${ }^{29}$, los Estados que se pronunciaron a favor subrayaron que se trataba del primer acuerdo global sobre la cooperación internacional en materia migratoria de toda la historia, que las migraciones habían contribuido poderosamente a la formación y desarrollo de varios de ellos (Canadá, Australia), que ningún Estado podía resolver el problema migratorio por sí solo y que no había nada que temer del pacto adoptado, ya que no tenía fuerza jurídica obligatoria ni establecía nuevos compromisos vinculantes para los Estados. Algunos Estados que votaron a favor, como en el caso de Austria, expresaron, sin embargo, serias reticencias con respecto al Pacto mundial sobre las migraciones.

Los Estados que votaron en contra o se abstuvieron, hicieron énfasis en que se trata de un ámbito primordial para salvaguardar su soberanía, que el Pacto no distingue suficientemente entre los migrantes regulares e irregulares, que su orientación pro migración puede tener un efecto llamada sobre los flujos migratorios, y que puede contribuir a incrementar la inseguridad en los países receptores al incluirse entre los migrantes posibles terroristas o criminales. Varios de los países que se pronunciaron en contra afirmaron además que el Pacto no les imponía obligación alguna que no fuera reconocida por ellos, que su libertad de acción para ordenar la política migratoria continuaba intacta y que no podrían derivarse del Pacto obligaciones que pasaran a formar parte del Derecho internacional consuetudinario.

28 A/CONF.231/15. Informe de la Comisión de verificación de poderes.

29 Ver: Nota de prensa GA/12113, General Assembly Endorses First-Ever Global Compact on Migration, Urging Cooperation among Member States in Protecting Migrants. 


\section{CONCLUSIÓN}

El régimen internacional relativo a las migraciones actualmente vigente resulta manifiestamente insuficiente para la regulación y gobernanza de los flujos migratorios. Los errores de enfoque en la concepción del sistema y, en particular, la colisión irreductible entre el derecho de las personas a salir de su país y el derecho de los Estados a rechazar la admisión en su territorio han llevado, en la práctica, a un círculo vicioso cuyos resultados son el aumento de la emigración irregular y la multiplicación de situaciones dramáticas que hieren los sentimientos humanitarios. En un mundo globalizado y cosmopolita, el aumento de las barreras físicas como vallas o muros, por altos que sean, o el rechazo del desembarco de los migrantes rescatados en el mar en un puerto seguro no podrán contener un fenómeno que tiene carácter sistémico en la sociedad internacional actual.

El complejo conjunto de elementos que conforman el fenómeno migratorio reclaman un nuevo marco de regulación y gobernanza internacional que responda con justicia y efectividad a los graves desafíos que se plantean. Las Naciones Unidas han puesto en marcha sendos procesos tendentes a elaborar un nuevo marco de regulación y gobernanza aplicable a los refugiados y a los migrantes. Los instrumentos adoptados, el Pacto mundial sobre los refugiados y el Pacto mundial para la migración segura, ordenada y regular, constituyen las piedras angulares de un sistema más eficaz y justo que los Estados deberán concertar en los próximos años. Esperemos que los sentimientos de solidaridad se impongan a los reflejos nacionalistas y que sea posible establecer un régimen internacional para las migraciones que nos saque del impasse actualmente existente. 
